\title{
Recognition of Focused Practice in Hospital Medicine Pilot Project
}

The American Board of Family Medicine (ABFM) is joining forces with the American Board of Internal Medicine (ABIM) to establish a pilot program for Recognition of Focused Practice (RFP) in hospital medicine. This pilot was approved by the American Board of Medical Specialties (ABMS) Board of Directors on September 23, 2009.

RFP in hospital medicine will use the current maintenance of certification (MOC) framework and would be the first customized MOC pathway that draws heavily on practice-based learning as its foundation. The pilot would engage hospitalists in uniquely designed part II, part III, and part IV tools that will be developed by the ABFM and ABIM.

Recent statistics indicate rapid growth and development in the field of hospital medicine, with approximately 20,000 hospitalists in the United States. "Given the significant number of family physicians working exclusively in the hospital setting, our board of directors felt it important to participate fully in this pilot with the ABIM," said James C. Puffer, MD, President and Chief Executive Officer of the ABFM. "We envision working together closely to develop the special tools used by our diplomates in this customized MOC pathway."

To attain hospital medicine recognition, ABFM diplomates must complete residency training in family medicine, be certified in family medicine, and participate in a practice that focuses primarily on hospital medicine for a minimum of 3 years. Diplomates interested in pursuing RFP may apply to the program in 2010. Approval for the program requires an attestation by the diplomate and a se- nior hospital officer that the diplomate meets thresholds for family medicine practice in the hospital setting and professional commitment to hospital medicine.

Program requirements for ABFM RFP in hospital medicine will include the following:

- Certification by the ABFM; diplomates must be in good standing and must maintain their primary certification in family medicine by the ABFM

- Currently valid, full, and unrestricted license to practice medicine in the United States or Canada

- Advanced Cardiac Life Support certification

- Minimum of 3 years of hospital medicine experience

- Attestation by the diplomate and a senior hospital officer that the diplomate meets thresholds for family medicine practice in the hospital setting and professional commitment to hospital medicine

- MOC activity comprising self-assessment of medical knowledge and practice performance relevant to hospital medicine

- Passing an ABFM MOC examination in hospital medicine

Completion of the program would identify diplomates as certified in family medicine with Focused Practice in Hospital Medicine. The pilot program will begin in the fall of 2010 .

Jane Ireland American Board of Family Medicine 